\title{
May minimally invasive plate osteosynthesis be an alternative to intramedullary nailing in selected spiral oblique and spiral wedge tibial shaft fractures?
}

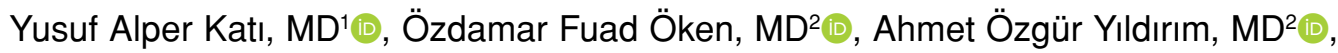 \\ Özkan Köse, $M^{1}{ }^{1}$, Melih Ünal, $M^{3}{ }^{3}$ \\ 'Department of Orthopedics and Traumatology, Antalya Training and Research Hospital, Antalya, Turkey \\ 2Department of Orthopedics and Traumatology, Ankara City Hospital, Ankara, Turkey \\ ${ }^{3}$ Department of Orthopedics and Traumatology, Yatağan State Hospital, Muğla, Turkey
}

Intramedullary nailing (IMN) and minimally invasive plate osteosynthesis (MIPO) are two commonly used surgical techniques that are superior to other available options (external fixation and conventional plate fixation) for the treatment of tibia shaft fractures. ${ }^{[1]}$ In a survey study among orthopedic surgeons, $90 \%$ of orthopedic trauma surgeons preferred IMN as their first choice for tibial shaft fracture fixation. ${ }^{[2]}$ Intramedullary nailing has several advantages over conventional open reduction and plating. First, they are biomechanically superior to plates as a load-sharing implant rather than a load-bearing implant. Second, the technique does not disturb the biology of fracture healing. However, it is not without complications and disadvantages. The major disadvantage is the difficulty in obtaining

Received: March 30, 2020

Accepted: June 18, 2020

Published online: September 11, 2020

Correspondence: Melih Ünal, MD. Yatağan Devlet Hastanesi Ortopedi ve Travmatoloji Kliniği, 48500 Yatağan, Muğla, Türkiye

E-mail: meliih.unal@gmail.com

Doi: $10.5606 /$ ehc. 2020.75052

Citation: Kałı YA, Öken ÖF, Yıldırım AÖ, Köse Ö, Ünal M. May minimally invasive plate osteosynthesis be an alternative to intramedullary nailing in selected spiral oblique and spiral wedge tibial shaft fractures? Jt Dis Relat Surg 2020;31(3):494-501.

(02020 All right reserved by the Turkish Joint Diseases Foundation

This is an open access article under the terms of the Creative Commons Attribution-NonCommercial License, which permits use, distribution and reproduction in any medium, provided the original work is properly cited and is not used for commercial purposes (http://creativecommons.org/licenses/by-nc/4.0/).

\section{ABSTRACT}

Objectives: This study aims to compare intramedullary nailing (IMN) and minimally invasive plate osteosynthesis (MIPO) treatment methods in Arbeitsgemeinschaft für Osteosynthesefragen (AO) 42A1 \& 42B1 selected tibial shaft fractures.

Patients and methods: Fifty-one patients ( 31 males, 20 females; mean age $43.5 \pm 14.2$ years; range, 18 to 81 years) operated for AO 42A1 or AO 42B1 tibial shaft fractures between January 2006 and January 2012 were retrospectively evaluated. Twenty-three of these patients were treated with MIPO and 28 with IMN. Patients were compared in terms of union time, return to work, infection, malunion, hospital stay, and sixth month and two-year Lower Extremity Functional Scale (LEFS) values.

Results: There was no difference between the MIPO and IMN groups in terms of demographic data, etiology, and fracture patterns. The mean follow-up time was $37.8 \pm 8.8$ months in MIPO group and $35.9 \pm 8.7$ months in IMN group. Union time $(\mathrm{p}=0.575)$, return to work $(\mathrm{p}=0.155)$, infection $(\mathrm{p}=0.643)$, malunion $(\mathrm{p}=0.471)$, and hospital stay $(\mathrm{p}=0.538)$ were all similar between groups. Although the LEFS value was higher in IMN group in sixth month $(\mathrm{p}=0.026)$, the two-year LEFS value was similar between groups $(\mathrm{p}=0.085)$.

Conclusion: Results of the study showed that both treatment methods are similar regarding clinical and functional outcomes. According to these results, MIPO can be recommended as an alternative to IMN in tibial shaft fractures formed as spiral oblique and spiral wedge.

Keywords: Intramedullary nailing, minimally invasive plate osteosynthesis, selected fractures, tibial shaft fracture.

and maintaining adequate reduction, particularly in proximal and distal shaft fractures with a large medullary canal. Some studies have shown higher rates of malalignment and delayed bone healing with IMN..$^{[3-6]}$ Another problem is the anterior knee pain, which may adversely affect the clinical results. To avoid these complications, plate fixation is advocated 
by several authors, particularly for proximal and distal tibial shaft fractures. ${ }^{[7-12]}$

Although conventional open reduction and plate fixation can achieve anatomic reduction and stable fixation, it is associated with a high rate of nonunion and infection. ${ }^{[13,14]}$ However, MIPO reduces the disadvantages of conventional plating and provides less soft tissue damage with better bone union, less wound healing, and infection problems. Moreover, it avoids anterior knee pain. As described above, IMN and MIPO have their own advantages and shortcomings.

In the literature, the best treatment option for tibial shaft fractures, particularly proximal and distal parts, remains a debate. ${ }^{[15]}$ In our opinion, the anatomy of the tibia and the type of fracture formation mechanism are two significant reasons for the debate. The tibial shaft was defined as the remaining area when a Müller square was removed from the proximal and distal of the tibia. ${ }^{[16]}$ However, the tibial segment defined as the shaft is not structurally homogeneous. There is no clear border between the middle of the shaft and the proximal or distal anatomical regions (Figure 1). ${ }^{[17]}$ These proximal and distal regions could be defined as

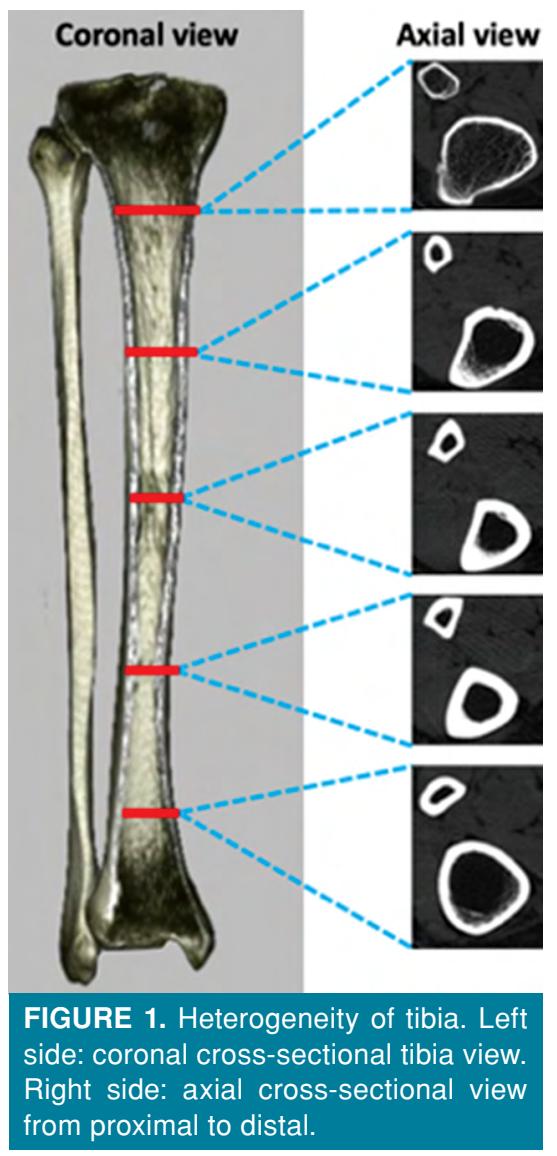

a transition zone regarding the width of the medullary canal and, the literature is still controversial in these regions of tibia fractures treatment. ${ }^{[3,4,7,8,18]}$ Particularly in the proximal and distal regions close to the joint, plates fixation are preferred, while in the middle region fractures of the shaft, nails are preferred. However, in this transition zone, both methods could be used and we simulated the indications for two devices (Figure 2). We believe that the treatment differences caused by this transitional zone might not be related only to the level of the fracture but also to the type of fracture formation mechanism. Spiral oblique and spiral wedge fractures do not occur with the same mechanisms as transverse fractures. These fractures occur as a result of torsional forces and, torsional forces could create long fracture lines that extend to metaphyseal areas. ${ }^{[19]}$ Plates have a higher torsional strength than IMNs and, those could be a more appropriate choice for spiral oblique and spiral wedge fractures. ${ }^{[19]}$ Therefore, in this study, we

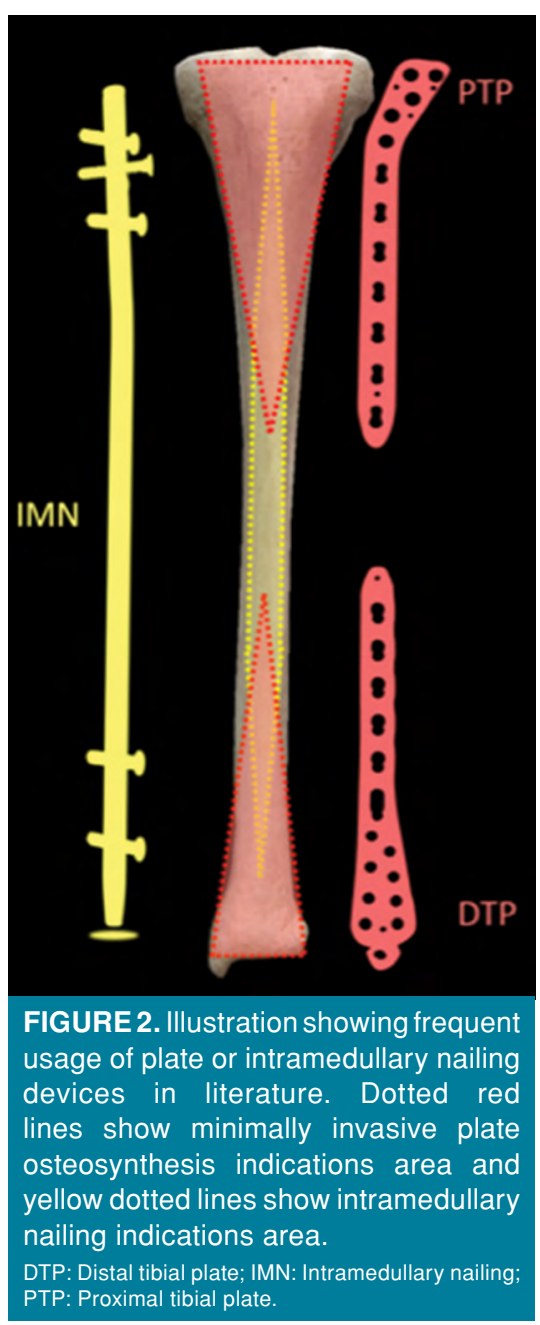


aimed treatment by classifying the tibia fractures according to the type of fracture formation rather than grouping them according to their proximal, middle or distal part. Accordingly, the whole tibia shaft [Arbeitsgemeinschaft für Osteosynthesefragen (AO)-42] was defined as the remaining area when a Müller square was removed from the proximal and distal of the tibia, and because of its formation mechanism, we particularly included spiral oblique and sprail wedge fractures. Thus, in this study, we aimed to compare IMN and MIPO treatment methods in $\mathrm{AO} 42 \mathrm{~A} 1$ \& $42 \mathrm{~B} 1$ selected tibial shaft fractures.

\section{PATIENTS AND METHODS}

This retrospective study included 51 patients (31 males, 20 females; mean age $43.5 \pm 14.2$ years; range, 18 to 81 years) who were treated for tibial shaft fractures in Ankara Numune Training and Research Hospital between January 2006 and January 2012. Demographic data of the patients, including age, sex, affected side, and mechanism of injury were obtained from the medical records. The fractures were classified according to the Gustilo-Anderson classification for open fractures and the Tscherne classification for closed fractures. The data related to the type of anesthesia, length of hospital stay, time from trauma to surgery, and operating time were also reviewed (Table I). Patients with AO 42A1 \& $42 \mathrm{~B} 1$ tibial fractures (all of proximal, middle and distal parts) treated either with MIPO or IMN were selected and included in the study. Of the 51 patients, 23 (14 males, 9 females; mean age, $49.2 \pm 15.9$ years) were treated with MIPO

\begin{tabular}{|c|c|c|c|c|c|}
\hline \multirow[b]{3}{*}{ Variable } & \multicolumn{4}{|c|}{$\begin{array}{l}\text { TABLE I } \\
\text { d preoperative clinical parameters }\end{array}$} & \multirow[b]{3}{*}{ Significance $(p)$} \\
\hline & \multicolumn{2}{|c|}{ MIPO group $(n=23)$} & \multicolumn{2}{|c|}{ IMN group $(n=28)$} & \\
\hline & $\mathrm{n}$ & Mean $\pm S D$ & $\mathrm{n}$ & Mean $\pm S D$ & \\
\hline Age (year) & & $49.2 \pm 15.9$ & & $38.6 \pm 13.3$ & 0.013 \\
\hline Sex & & & & & 0.610 \\
\hline Male & 14 & & 17 & & \\
\hline Female & 9 & & 11 & & \\
\hline Side & & & & & 0.137 \\
\hline Right & 10 & & 7 & & \\
\hline Left & 13 & & 21 & & \\
\hline Mechanism of injury & & & & & 0.363 \\
\hline Traffic accident & 16 & & 15 & & \\
\hline Simple fall & 4 & & 8 & & \\
\hline Gunshot injury & 1 & & 0 & & \\
\hline Fall from height & 2 & & 5 & & \\
\hline$A O$ classification (42A1/42B1) & & & & & 0.294 \\
\hline $42 \mathrm{~A} 1$ & 10 & & 9 & & \\
\hline 42B1 & 13 & & 19 & & \\
\hline Gustillo-Anderson classification & & & & & 0.853 \\
\hline Type 1 & 4 & & 3 & & \\
\hline Type 2 & 5 & & 5 & & \\
\hline Type 3 & 1 & & 1 & & \\
\hline Tscherne classification & & & & & 0.657 \\
\hline Grade 0 & 6 & & 13 & & \\
\hline Grade 1 & 5 & & 4 & & \\
\hline Grade 2 & 1 & & 1 & & \\
\hline Grade 3 & 1 & & 1 & & \\
\hline Type of anesthesia & & & & & 0.228 \\
\hline General & 14 & & 13 & & \\
\hline Spinal & 9 & & 15 & & \\
\hline Time between injury to operation (day) & & $5.0 \pm 3.7$ & & $4.6 \pm 2.8$ & 0.666 \\
\hline Duration of operation (min) & & $50.2 \pm 16.4$ & & $49.4 \pm 14.8$ & 0.866 \\
\hline
\end{tabular}


and 28 (17 males, 11 females; mean age, 38.6 \pm 13.3 years) with IMN. Patients with pathological fractures, immobilized patients, and other surgical techniques such as external fixation were excluded. The study protocol was approved by the Ankara Numune Training and Research Hospital Ethics Committee (Approval date and no: 2011-272). A written informed consent was obtained from each patient. The study was conducted in accordance with the principles of the Declaration of Helsinki.

All operations were performed by two experienced surgeons with the patient in the supine position (Figures 3 and 4). Standard emergency debridement and irrigation were applied to all open fractures. Patients with an extremity alignment problem and those with open or closed fracture with evident soft tissue damage were followed-up with skeletal traction or applied external fixation until definitive surgery. Fibular plate fixation was performed, if there was a distal third fibula fracture for both groups. Indirect reduction techniques were
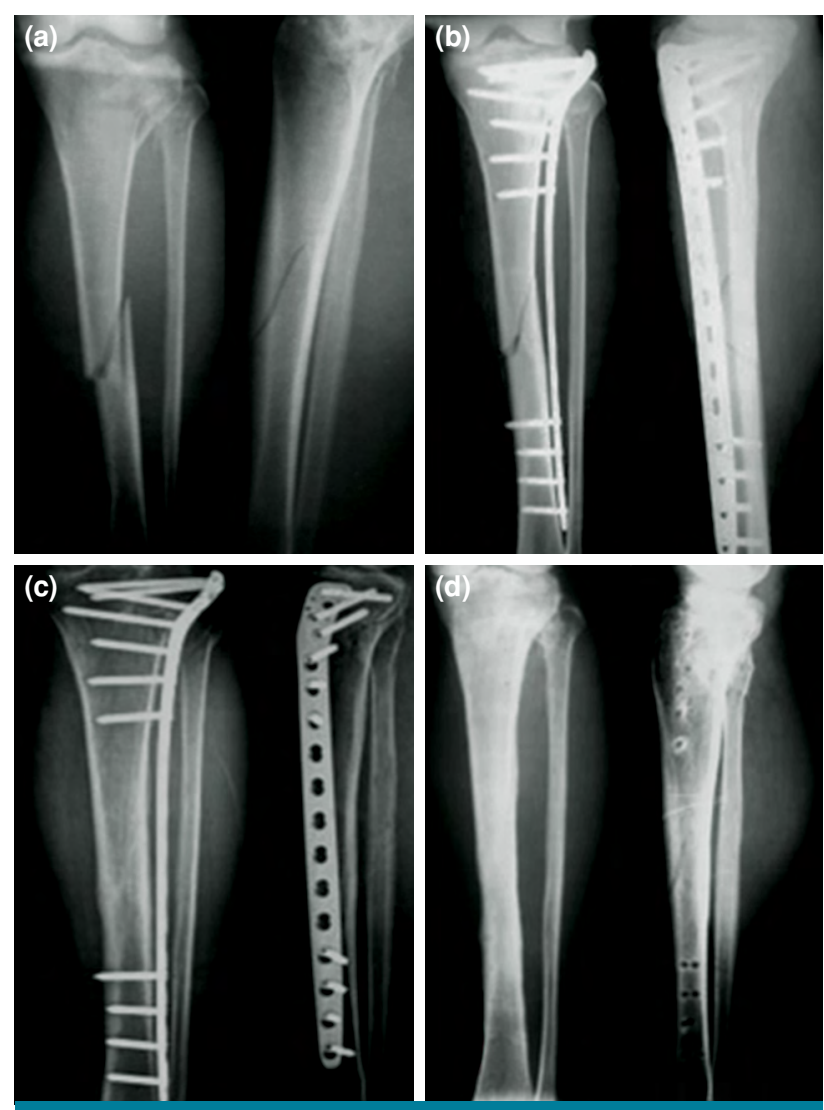

FIGURE 3. Patient treated with minimally invasive plate osteosynthesis. (a) Preoperative. (b) Postoperative fourth month. (c) Postoperative $32^{\text {nd }}$ month. (d) Radiograph after removal of plate. applied to obtain a closed reduction in both groups. When postoperative edema and pain control was required, a short-leg cast was applied for a week.

Patients were followed-up at third and sixth weeks and then at six-week intervals until the fracture union. Fracture healing was defined as no pain in the fracture area, and the visualization of callus tissue in at least three of the four cortices on radiographs. ${ }^{[20]}$ Patients were encouraged for weight bearing based on the fracture healing on radiographs and clinical examination. At the final follow-up (at least 24 months), functional evaluation was performed using the Lower Extremity Functional Scale (LEFS). The LEFS was applied preoperatively by asking the patient about the pre-fracture status of the extremity, and at six months and two years postoperatively. Time to the union, time to return to work, infection, and malunion were recorded.

\section{Statistical analysis}

Statistical analysis was performed using the IBM SPSS version 23.0 software (IBM Corp., Armonk, NY, USA). Continuous variables were stated as mean \pm standard deviation and median values, and categorical values as number (n) and percentage (\%). The comparisons of independent continuous variables were performed using the Student's t-test or the Mann-Whitney $U$ test according to the normality of distribution. The chi-square test was applied in the comparisons of categorical data. A $p$ value of $<0.05$ was accepted as statistically significant.

\section{RESULTS}

According to the demographic data, apart from the parameter of age, there was no significant difference between the groups in respect to sex, affected side, and mechanism of injury (Table I).

When the distribution of $\mathrm{AO} 42 \mathrm{~A} 1$ and 42B1 fractures was examined, which were both thought to be suitable for both treatment methods, the A group fractures were seen to be equally distributed in both groups, and there were more B group fractures in IMN group, while the difference was not statistically significant $(p=0.294)$. Both groups were similar according to the open and closed fracture classifications. There was no difference between the groups in respect of the application of general anesthesia and spinal anesthesia $(p=0.228)$. The time from trauma to surgery $(\mathrm{p}=0.666)$ and operating time $(\mathrm{p}=0.866)$ were similar in both groups (Table I). 


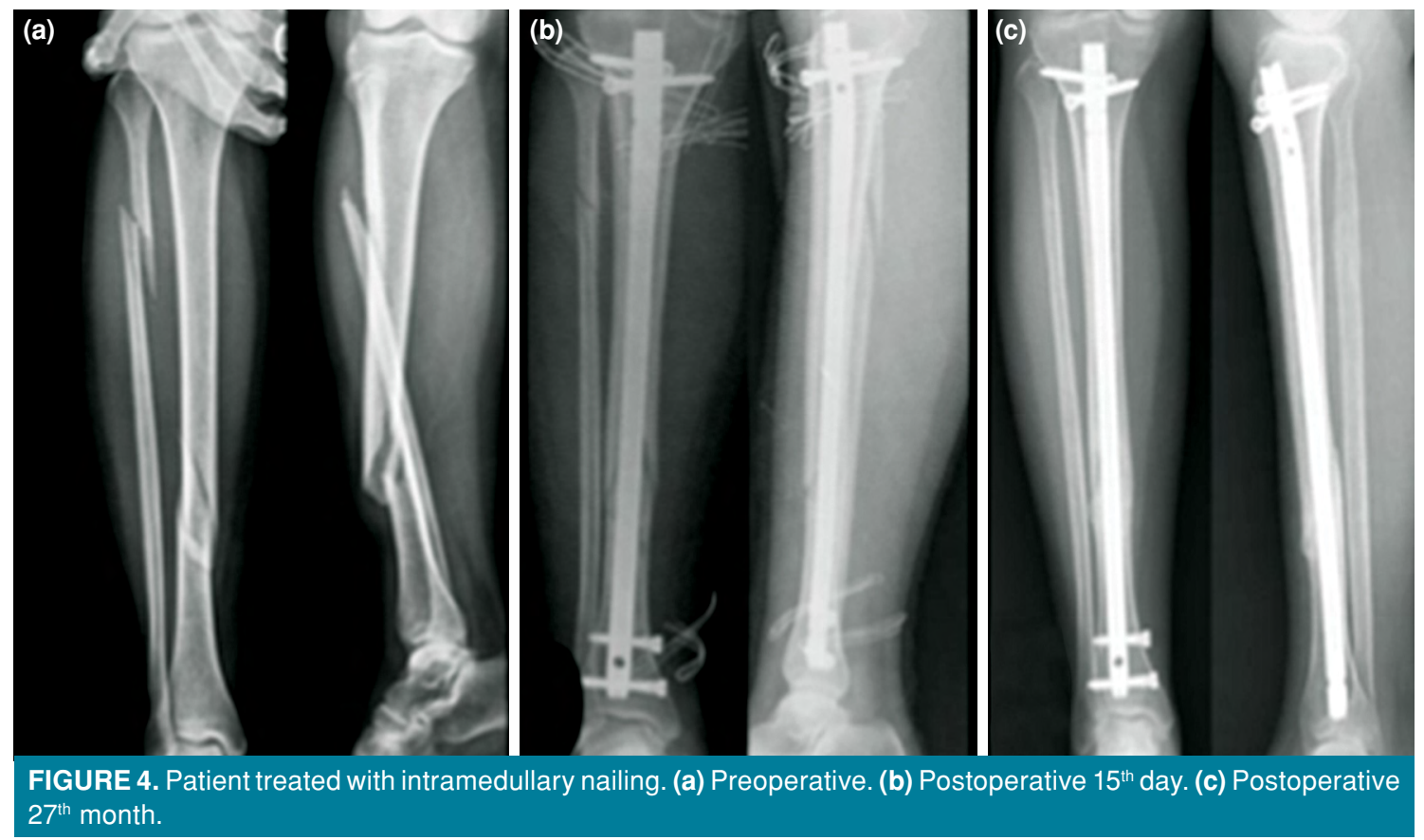

The mean follow-up period was $37.8 \pm 8.8$ weeks in MIPO group and $35.9 \pm 8.7$ weeks in IMN group. The radiological visualization of callus formation was similar in both groups ( $\mathrm{p}=0.575)$. No difference was determined between the groups in respect of return to work $(\mathrm{p}=0.155)$. No infection developed in 20 of the 23 patients in MIPO group and in 24 of the 28 patients in IMN group. Rates of malunion were similar in both groups $(p=0.471)$. According to the LEFS results at six months, the rate of those classified as very good was higher in IMN group than in MIPO group ( $p=0.026)$. At the end of two years, the results of MIPO group showed a higher increase, while the two-year functional results were similar in both groups $(\mathrm{p}=0.085)$ (Table II).

\begin{tabular}{|c|c|c|c|c|c|}
\hline \multicolumn{6}{|c|}{$\begin{array}{c}\text { TABLE II } \\
\text { Summary of results }\end{array}$} \\
\hline \multirow[b]{2}{*}{ Variable } & \multicolumn{2}{|c|}{ MIPO group $(n=23)$} & \multicolumn{2}{|c|}{ IMN group $(n=28)$} & \multirow[b]{2}{*}{ Significance $(p)$} \\
\hline & $\mathrm{n}$ & Mean \pm SD & $\mathrm{n}$ & Mean \pm SD & \\
\hline Follow-up (month) & & $37.8 \pm 8.8$ & & $35.9 \pm 8.7$ & 0.448 \\
\hline Union time (week) & & $15.1 \pm 1.8$ & & $14.7 \pm 2.3$ & 0.575 \\
\hline Return to work (week) & & $16.9 \pm 1.8$ & & $16.0 \pm 2.4$ & 0.155 \\
\hline Infection & & & & & 0.643 \\
\hline None & 20 & & 24 & & \\
\hline Superficial & 3 & & 3 & & \\
\hline Deep & 0 & & 1 & & \\
\hline Malunion & & & & & 0.471 \\
\hline Yes & 3 & & 5 & & \\
\hline No & 20 & & 23 & & \\
\hline Hospital stay (day) & & $9.4 \pm 3.6$ & & $8.8 \pm 3.0$ & 0.538 \\
\hline LEFS sixth month follow-up & & $66.7 \pm 5.1$ & & $69.6 \pm 3.8$ & 0.026 \\
\hline LEFS second year follow-up & & $70.4 \pm 5.9$ & & $72.9 \pm 4.2$ & 0.085 \\
\hline
\end{tabular}




\section{DISCUSSION}

In this study, the clinical and functional results of patients treated with MIPO or IMN for spiral oblique and spiral wedge tibial shaft fractures were compared, and the data revealed no statistically significant difference in either technique with respect to clinical and functional results. Demographic and preoperative clinical parameters were similar in each group in terms of mechanisms of injury, fracture types, and characteristics. MIPO group had a lower malunion rate than IMN groups, but there was no significant difference between the two groups. IMN group had a significantly higher LEFS value than MIPO group in the sixth month follow-up, while the difference in LEFS values between the two groups were similar at the end of the second year. The other parameters were similar in both groups.

One of the most critical limitations of IMN is the difficulty in obtaining and maintaining adequate reduction. In the middle of the tibia shaft, a sufficient alignment could be achieved with nails, but this area is a short segment. ${ }^{[21]}$ The proximal or distal part of the shaft is heterogeneous and, IMN cannot contact the tibial cortex in these zones. In that case, the maintenance of the reduction depends only on the fixation of the locking nails at both ends. Therefore, the fixation of IMN is relatively weak and has poor torsional stability. ${ }^{[19]}$ Prior studies of proximal or distal tibia fractures have found more angular malalignment with IMN versus plates. ${ }^{[3,22,23]}$ High-level surgical skills are required to obtain the correct alignment with a nail. ${ }^{[24,25]}$ The use of distal multi-axial locking screws, poller screws, and percutaneous reduction techniques could increase the stability and quality of reduction. However, these procedures lead to longer surgical time, more blood loss, and more fluoroscopy time. ${ }^{[1,26]}$ Reaming could provide better stability, but it is also possible that reamed IMN results in delayed healing because of damage to the medullary blood supply. ${ }^{[3]}$ Malalignment was also associated with ankle pain related to the close anatomic neighboring to the ankle. Distal tibia malalignment has been associated with more ankle pain and degenerative changes. ${ }^{[27,28]}$ For these reasons, in the treatment of spiral oblique and spiral wedge tibia shaft fractures where reduction is difficult to obtain, MIPO may be preferred for greater stability and better alignment. Our results show that clinical and functional results between the two methods are similar and support this proposal.

The MIPO is the other option for the treatment of tibial shaft fractures. In the literature, comparisons of fractures applied plating and IMN have shown that plate application provides better alignment ${ }^{[4,6,26]}$ since plates (particularly MIPO) are produced and countered according to the anatomy on the surface of the tibial cortex, while IMNs are produced as a standard design for the canal. Additionally, the torsional stability in plates is better than IMNs. ${ }^{[19]}$ Bending type injury, which is one of the underlying mechanisms of fracture, often creates transverse fractures in long bones. In transverse fractures, the nail could provide a biomechanical advantage. However, in torsional injuries (e.g. 42A1 and 42B1), the fractures are mostly spiral oblique and spiral wedge. The stability needed by the fracture could be achieved with a plate that is more resistant for torsional forces. ${ }^{[29]}$

According to basic $\mathrm{AO}$ surgical techniques, if fixation with plate is preferred in simple long bone fractures, compression and absolute stability should be required. The plate is used for neutralization after the compression screw placement. ${ }^{[29]}$ On the contrary, in our study, we used MIPO with relative stability for tibia shaft fracture because we thought that we could achieve better reduction and alignment in spiral oblique and spiral wedge tibial shaft fractures with MIPO. All patients in our study had spiral oblique and spiral wedge fractures. Hasenboehler et al. ${ }^{[30]}$ stated in his study that a small group of simple tibial shaft fractures was healed by relative stability. However, he believed that the bridge plating technique in simple fractures is disadvantageous due to prolonged time to full weight bearing. In another study, successful results were reported by obtaining relative stability with MIPO after anatomical reduction, and the success of the MIPO method has been associated with the angular stability of long locking plates. ${ }^{[5]}$ In this group, weight bearing was allowed because the locking plate systems act as a monobloc construct. Shen et al. ${ }^{[19]}$ put forward their successful results on the modified MIPO method described by themselves in distal shaft fractures. Accordingly, they obtained anatomical reduction by MIPO method as described in the study and achieved excellent results without compression. They also reported that MIPO provides both shorter surgical time and less damage to biology. In our study, we obtained anatomical fracture reduction and did not use compression techniques in these fractures with MIPO.

Significant confusions with the treatment of tibial fractures are caused due to the differences in the definition of the shaft. While tibia shaft fractures were classified as $\mathrm{AO} 42$, according to Adam et al., ${ }^{[5]}$ very similar fractures were classified as $\mathrm{AO} 43$, according to Shen et al. ${ }^{[19]}$ Commonly, there were two types of definitions for the proximal or distal tibia fracture found in literature. Some authors defined 
distal or proximal tibial metaphysis as the area within two Müller squares of the ankle joint, in which the proximal and the distal segments of long bones were defined by a square whose sides had the same length as the widest part of the epiphysis. ${ }^{[16,31,32]}$ Another description of the distal tibial fracture was located between $3 \mathrm{~cm}$ and $12 \mathrm{~cm}$ from the tibial plafond. A similar description for proximal tibia fracture was located between $4 \mathrm{~cm}$ and $11 \mathrm{~cm}$ from the tibial plateau. ${ }^{[3,6]}$ Considering the slightly different criteria for the definition of tibia shaft fractures, there were different definitions for the same fractures, according to $\mathrm{AO}$ in some studies. ${ }^{[3,5,17]}$ In our opinion, subgroup analysis based on AO/Orthopaedic Trauma Association (OTA) classification is reasonable, and we classified all the tibia shaft fractures as $42 \mathrm{~A} 1$ and 42B1, regardless of whether they were proximal or distal, because our recommendation was to prefer the MIPO method according to the fracture formation mechanism, not the fracture level.

In our study, we aimed to compare the long-term results of the two methods. Therefore, we evaluated only the results of infection, hospitalization, and radiological union in the short term. Those results were similar between the two groups. In the long term, IMN would be associated with more knee pain, while MIPO would be associated with pain from implant prominence, and both of them would be associated with more ankle pain. ${ }^{[22]}$ However, since these results were not objective and measurable, LEFS was used to measure the results more accurately. A literature review for the functional evaluations of these two fixation methods revealed differences between the scoring systems used. In previous studies in the literature, functional outcomes have been evaluated using scoring systems such as LEFS, the Foot Function Index, Olerud and Molander Ankle Score, and Disability Rating Index. ${ }^{[22,31,33]}$ We chose LEFS because the questions were clear allowing evaluating past activities very well. In addition, the LEFS score used in this study is appropriate in the clinical follow-up of lower extremity traumatic injuries. The applicability of both Short-Form 36 and LEFS has been previously shown in the clinical follow-up of lower extremity traumatic injuries. ${ }^{[3,35]}$ In the current study, according to LEFS in the short-term at six months, the functional results were determined to be better with IMN fixation. It was thought that this could be a biomechanical advantage of IMN in the short term. However, as the follow-up period progressed, the LEFS results of the MIPO group caught up with those of the IMN group.
The MIPO is an alternative method for some selected cases. Primarily, it may be considered as an alternative fixation method in polytrauma patients to avoid pulmonary complications. Also, it could be considered as a definitive fixation instead of temporary fracture fixation by external fixators. ${ }^{[17]}$ Minimally invasive plate osteosynthesis could be an alternative if blocking screw, distal locking screw, and percutaneous reduction technique are unavailable in IMN practice. ${ }^{[23]}$ In addition to these indications, we think that MIPO could be an alternative to IMN in spiral oblique and spiral wedge tibia shaft fractures.

Our study has inherent weaknesses and limitations. Firstly, the study involves prospectively collected data on retrospectively identified patients, and the number of patients was relatively low. Secondly, we had no data regarding time to full weight bearing and time of union (clinically) in both groups. Thirdly, we used relative stability fixation, although it is not primarily indicated instead of the absolute stability principles. On the other hand, although these two methods have been compared enough before, the clinical content of our study is different. The mean follow-up period of 36.8 months was much more extended than the previous studies. In these fractures, there are no studies suggesting treatment methods according to the type of fracture. Finally, prospective controlled clinical studies are needed for the indication of MIPO in the treatment of these fractures.

In conclusion, IMN and MIPO are both safe and effective methods in treating tibia shaft fractures, and our results show that both methods provide similar clinical and functional results. According to these results, MIPO can be recommended as an alternative to IMN in tibial shaft fractures formed as spiral oblique and spiral wedge because it provides better alignment and high torsional stability.

\section{Declaration of conflicting interests}

The authors declared no conflicts of interest with respect to the authorship and/or publication of this article.

\section{Funding}

The authors received no financial support for the research and/or authorship of this article.

\section{REFERENCES}

1. Wang JQ, Chen ZX, Guo WJ, Zhao YM, Peng Luo. Comparison of plate and intramedullary nail fixation of extra-articular tibial fractures: A retrospective study exploring hidden blood loss. Injury 2019;50:546-50.

2. Johal $\mathrm{H}$, Bhandari $\mathrm{M}$, Tornetta $\mathrm{P}$ 3rd. Cochrane in CORR®: Intramedullary Nailing for Tibial Shaft Fractures in Adults (Review). Clin Orthop Relat Res 2017;475:585-91. 
3. Vallier HA, Le TT, Bedi A. Radiographic and clinical comparisons of distal tibia shaft fractures $(4$ to $11 \mathrm{~cm}$ proximal to the plafond): plating versus intramedullary nailing. J Orthop Trauma 2008;22:307-11.

4. Vallier HA, Cureton BA, Patterson BM. Randomized, prospective comparison of plate versus intramedullary nail fixation for distal tibia shaft fractures. J Orthop Trauma 2011;25:736-41.

5. Adam P, Bonnomet F, Ehlinger M. Advantage and limitations of a minimally-invasive approach and early weight bearing in the treatment of tibial shaft fractures with locking plates. Orthop Traumatol Surg Res 2012;98:564-9.

6. Liu XK, Xu WN, Xue QY, Liang QW. Intramedullary nailing versus minimally invasive plate osteosynthesis for distal tibial fractures: a systematic review and meta-analysis. Orthop Surg 2019;11:954-65.

7. Phisitkul P, McKinley TO, Nepola JV, Marsh JL. Complications of locking plate fixation in complex proximal tibia injuries. J Orthop Trauma 2007;21:83-91.

8. Lang GJ, Cohen BE, Bosse MJ, Kellam JF. Proximal third tibial shaft fractures. Should they be nailed? Clin Orthop Relat Res 1995;(315):64-74.

9. Redfern DJ, Syed SU, Davies SJ. Fractures of the distal tibia: minimally invasive plate osteosynthesis. Injury 2004;35:615-20.

10. Helfet DL, Shonnard PY, Levine D, Borrelli J Jr. Minimally invasive plate osteosynthesis of distal fractures of the tibia. Injury 1997;28 Suppl 1:A42-7.

11. Meena RC, Meena UK, Gupta GL, Gahlot N, Gaba S. Intramedullary nailing versus proximal plating in the management of closed extra-articular proximal tibial fracture: a randomized controlled trial. J Orthop Traumatol 2015;16:203-8.

12. Kandemir U, Herfat S, Herzog M, Viscogliosi P, Pekmezci M. Fatigue failure in extra-articular proximal tibia fractures: Locking intramedullary nail versus double locking plates-a biomechanical study. J Orthop Trauma 2017;31:e49-e54.

13. Janssen KW, Biert J, van Kampen A. Treatment of distal tibial fractures: plate versus nail: a retrospective outcome analysis of matched pairs of patients. Int Orthop 2007;31:709-14.

14. Zou J, Zhang W, Zhang CQ. Comparison of minimally invasive percutaneous plate osteosynthesis with open reduction and internal fixation for treatment of extraarticular distal tibia fractures. Injury 2013;44:1102-6.

15. Beytemür O, Albay C, Adanır O, Yüksel S, Güleç MA. Is intramedullary nailing applicable for distal tibial fractures with ankle joint extension? Eklem Hastalik Cerrahisi 2016;27:125-31.

16. Müller ME, Nazarian S, Koch $\mathrm{P}$, Schatzker J. The Comprehensive Classification of Fractures of Long Bones. 1st ed. Berlin: Springer-Verlag Berlin Heidelberg; 1990.

17. Gosman JH, Hubbell ZR, Shaw CN, Ryan TM. Development of cortical bone geometry in the human femoral and tibial diaphysis. Anat Rec (Hoboken) 2013;296:774-87.

18. Galal S. Minimally invasive plate osteosynthesis has equal safety to reamed intramedullary nails in treating GustiloAnderson type I, II and III-A open tibial shaft fractures. Injury 2018;49:866-70.

19. Shen J, Xu J, Tang MJ, Luo CF, Zhang CQ. Extraarticular distal tibia facture (AO-43A): A retrospective study comparing modified MIPPO with IMN.
Injury 2016;47:2352-9.

20. Im GI, Tae SK. Distal metaphyseal fractures of tibia: a prospective randomized trial of closed reduction and intramedullary nail versus open reduction and plate and screws fixation. J Trauma 2005;59:1219-23.

21. Duygun F, Aldemir C. Effect of intramedullary nail compression amount on the union process of tibial shaft fracture and the evaluation of this effect with a different parameter. Eklem Hastalik Cerrahisi 2018;29:87-92.

22. Vallier HA, Cureton BA, Patterson BM. Factors influencing functional outcomes after distal tibia shaft fractures. J Orthop Trauma 2012;26:178-83.

23. Xue XH, Yan SG, Cai XZ, Shi MM, Lin T. Intramedullary nailing versus plating for extra-articular distal tibial metaphyseal fracture: a systematic review and metaanalysis. Injury 2014;45:667-76.

24. Kulkarni SG, Varshneya A, Kulkarni S, Kulkarni GS, Kulkarni MG, Kulkarni VS, et al. Intramedullary nailing supplemented with Poller screws for proximal tibial fractures. J Orthop Surg (Hong Kong) 2012;20:307-11.

25. Höntzsch D, Blauth M, Attal R. Winkelstabile Verriegelung von Marknägeln mit dem Angular Stable Locking System ${ }^{\circledR}$ (ASLS) [Angle-stable fixation of intramedullary nails using the Angular Stable Locking System ${ }^{\circledR}$ (ASLS)]. Oper Orthop Traumatol 2011;23:387-96.

26. Minhas SV, Ho BS, Switaj PJ, Ochenjele G, Kadakia AR. A comparison of 30-day complications following plate fixation versus intramedullary nailing of closed extraarticular tibia fractures. Injury 2015;46:734-9.

27. Milner SA, Davis TR, Muir KR, Greenwood DC, Doherty M. Long-term outcome after tibial shaft fracture: is malunion important? J Bone Joint Surg [Am] 2002;84:971-80.

28. van der Schoot DK, Den Outer AJ, Bode PJ, Obermann WR, van Vugt $A B$. Degenerative changes at the knee and ankle related to malunion of tibial fractures. 15-year follow-up of 88 patients. J Bone Joint Surg [Br] 1996;78:722-5.

29. Gueorguiev-Rüegg B, Stoddart M. Biology and biomechanics in bone healing. In: Buckley RE, Moran CG, Apivatthakakul T, editors. AO Principles of Fracture Management. 3rd ed. Davos: Thieme; 2018. p. 9-26.

30. Hasenboehler E, Rikli D, Babst R. Locking compression plate with minimally invasive plate osteosynthesis in diaphyseal and distal tibial fracture: a retrospective study of 32 patients. Injury 2007;38:365-70.

31. Mauffrey C, McGuinness K, Parsons N, Achten J, Costa ML. A randomised pilot trial of "locking plate" fixation versus intramedullary nailing for extra-articular fractures of the distal tibia. J Bone Joint Surg [Br] 2012;94:704-8.

32. Kuo LT, Chi CC, Chuang CH. Surgical interventions for treating distal tibial metaphyseal fractures in adults. Cochrane Database Syst Rev 2015;3:CD010261.

33. Polat A, Kose O, Canbora K, Yanık S, Guler F. Intramedullary nailing versus minimally invasive plate osteosynthesis for distal extra-articular tibial fractures: a prospective randomized clinical trial. J Orthop Sci 2015;20:695-701.

34. Pan SL, Liang HW, Hou WH, Yeh TS. Responsiveness of SF-36 and Lower Extremity Functional Scale for assessing outcomes in traumatic injuries of lower extremities. Injury 2014;45:1759-63.

35. Smith MV, Klein SE, Clohisy JC, Baca GR, Brophy RH, Wright RW. Lower extremity-specific measures of disability and outcomes in orthopaedic surgery. J Bone Joint Surg [Am] 2012;94:468-77. 